\title{
Bahía de Banderas: nuevo municipio, vieja democracia
}

\author{
Bertha A. Villaseñor $P$. \\ UNIVERSIDAD AUTÓNOMA DE NAYARIT
}

UBICACIÓN GEOGRÁFICA Y POBLACIÓN

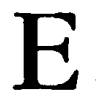

1 municipio número 20 del estado de Nayarit, creado en 1989 y denominado Bahía de Bande. ras, se encuentra ubicado en la parte sureste de la entidad; limita al norte con el municipio de Compostela, al sur y oriente con el estado de Jalisco - destacando su vecindad con Puerto Vallarta- y al poniente con el océano Pacífico, mismo que le proporciona $44.1 \mathrm{~km}$ de litorales.

Dentro de los límites del nuevo municipio se localizan las llanuras de Bahía de Banderas, las cuales cuentan con una extensión de $110 \mathrm{~km}^{2}$, lugar donde se han construido los vasos de almacenamiento de agua destinados a los sistemas de riego, sobre todo en las localidades de la margen izquierda de la carretera federal núm. 200, 'TepicPuerto Vallarta, y la parte costera, en la margen derecha de la misma, se ha dedicado a la actividad turística, creando en ella verdaderos complejos hoteleros como el de Nuevo Vallarta, Bucerías, Cruz de Huanacaxtle, Jarretade. ras y otros. ${ }^{1}$

Las principales actividades económicas que se desarrollan en el municipio son la agricultura -con productos tales como frijol, tabaco, sorgo, maíz y frutas-, la ganadería, la pesca y

${ }^{1}$ Secretaría de Programación y Presupuesto, Estudio, 1990. 
el turismo. Este último ha provocado un crecimiento urbano y poblacional, con su consecuente infraestructura de mantenimiento y de prestación de servicios.

Actualmente son las localidades costeras de este municipio las que reciben la mayor cantidad de inversión -ya sea pública o privada, nacional o extranjera-dedicada a la construcción de infraestructura urbana y turística para incrementar la oferta de servicios, especialmente al gran turismo nacional e internacional.

La población total del municipio es, en el año de 1990, de aproximadamente 40788 personas; de éstas, un $51 \%-20811$ personas- son hom. bres y un $49 \%$ son mujeres -19977 en total. Por otra parte, considerando a esta misma población por grupos de edad, encontramos que el municipio cuenta con una población relativamente joven, ya que $66 \%$ del total de la misma tiene edades que oscilan entre los 0 y los 24 años de edad, un 15.7\% lo constituyen personas cuyas edades fluctúan entre 25 y 39 años, mientras que los de 40 a 59 años representan un $11.9 \%$ y los de 60 años o más representan $5.6 \%$ de la población total.

\section{CAUSAS DE LA CREACIÓN DEL} NUEVO MUNICIPIO

La demanda de crear el nuevo municipio no era nueva, estaba latente

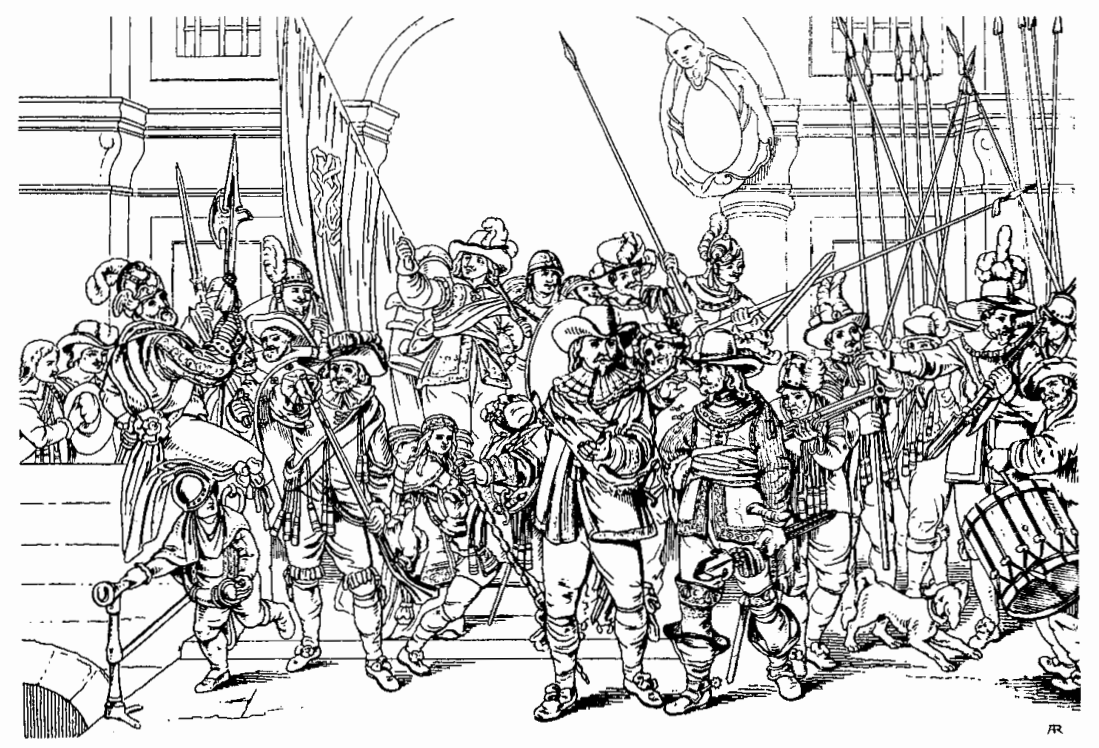


en la población desde muchos años atrás, pero fue retomada durante la campaña para gobernador de Celso Humberto Delgado Ramírez, mismo que al asumir la gubernatura, manifestó el propósito de realizar el proceso de consulta popular.

En septiembre de 1989, los pobla. dores de Bucerías se congregaron para demandar la creación -aun cuando ya los pasos legales se iban cumpliendodel municipio. Fue en ese mismo acto que pidieron tuviera su cabecera precisamente en dicha localidad. ${ }^{2}$

Uno de los principales argumentos que se plantearon para la creación del nuevo municipio fue la concentración de funciones que se daba en la cabecera municipal -del municipio de Compostela- y, junto a esto, la falta de vías y medios de comunicación que facilitaran el acceso desde las localidades más apartadas del municipio, según versiones manifestadas por los pobladores.

Otro de los propósitos que se mencionaron fue

el propiciar la planeación regional y descentralización, fortaleciendo la vida democrática de los municipios, mediante estructuras propias de poder y dirección que garanticen la activa participación en la toma de decisiones que les competen. ${ }^{3}$

Acerca de esos argumentos, el gobierno estatal emprendió la tarea de lograr el consenso de la población en cuanto a las ventajas de la creación del

2 El Nacional, 24 de septiembre 1989.

3 XII Legislatura, Nuestros, 1989, p. 9. nuevo municipio, planteando también la posibilidad de incorporarse de ma. nera más rápida al proceso de modernización de la vida nacional, lo que vendría a aportar mayores beneficios para toda la población del nuevo municipio.

\section{MaRCo legal. De la CRFACIÓN}

La creación del nuevo municipio ha te. nido como marco legal, en primer lugar, las reformas al artículo 115 constitucional impulsadas por el gobierno de Miguel de la Madrid, las cuales fueron aprobadas en febrero de 1983.

Con base en el planteamiento de la necesidad de llevar a cabo la descentralización administrativa y de funciones, de dar a cada nivel de gobierno el papel que le corresponde y de acercar la gestión municipal a los habitantes, se promovió en Nayarit la creación de un nuevo municipio.

En el acto de expedición de la convocatoria para la consulta popular acerca de la creación del nuevo municipio, se planteó, como ya se había scñalado antes, que

el fundamento histórico, político y jurídico de dicha convocatoria es la reforma municipal del presidente Miguel de la Madrid, cuyos propósitos son muy claros: evitar que voluntades ajenas dirijan los destinos municipales, y sus ayuntamientos $[\ldots]$ son responsables directos del cumplimiento de la reforma municipal. ${ }^{4}$

${ }^{4}$ Ibid. 
Para la consulta popular, el Congreso del estado, por medio de una comisión especial, organizó un calendario de audiencias públicas: del 8 al 14 de febrero de 1988 en catorce localidades de la zona sur de Compostela.

Los resultados de estas audiencias públicas fueron remitidos al pleno del Congreso del estado, donde, como resultado de una primera discusión, se manifestó la posibilidad de crear el municipio número. 20 en la zona sur del estado.

En diciembre de 1989 el Congreso del estado informó a la opinión pública que el procedimiento para la creación del nuevo municipio había estado, en todo momento, apegado al marco juridico:

De acuerdo con las disposiciones constitucionales y legales respectivas, el Congreso del estado discutió y aprobó, en todos sus términos, la minuta del decreto número 7261 , el día 11 de diciembre del presente año, mediante el cual la Legislatura aprobó, en lo general y de manera unánime [...] la creación del municipio de Bahía de Banderas y la adición del artículo $3^{\circ}$ de nuestra Cons. titución Política. 5

Posteriormente, a mediados de 1990, el mismo Congreso aprobó la Ley de Ingresos del municipio de Bahía de Banderas; el proyecto de la misma se hizo tomando en cuenta los conceptos y tarifas que el municipio de Compostela mantenía en vigor. Esta ley estaría vigente durante un -año, 1989.

5 Realidades, Tepic, 14 de diciembre de y después, de acuerdo con las necesidades del nuevo municipio, se iría modificando. 6

\section{NUEVO MODELO ADMINISTRATTVO}

En el país, de manera general descle la década pasada, se empieza a reconocer la existencia de fuertes problemas regionales, de concentración espacial y de centralización de funciones. Todo esto resultado de un proceso histórico donde el Estado ha jugado un papel central.

Sin embargo, este reconocimiento parece haber dejado de lado el nivel municipal de gobierno. Sólo cuando se agravan los conflictos -principalmente los políticos-a este nivel, surge la crisis de los poderes tradicionales y se intensifican las luchas electorales, se vuelven los ojos a los municipios y se piensa en fortalecerlos.

Lo que parece estar detrás de la decisión de crear un nuevo municipio en la región de Bahía de Banderas es la necesidad de instaurar un nuevo modelo administrativo, técnicamente más moderno, con la participación de actores pegados a tales técnicas, capaces de romper el esquema tradicional del poder. Todo esto de acuerdo con el surgimiento de un nuevo modelo de acumulación que responde a la dinámica socioeconómica que se está generando en la región, gracias a las inversiones extranjeras en infraestructura turística y al impulso a la ganadería y a la agricultura de exportación. principalmente.

${ }^{6}$ ElObservador, Tepic, 10 de mayo de 1990. 


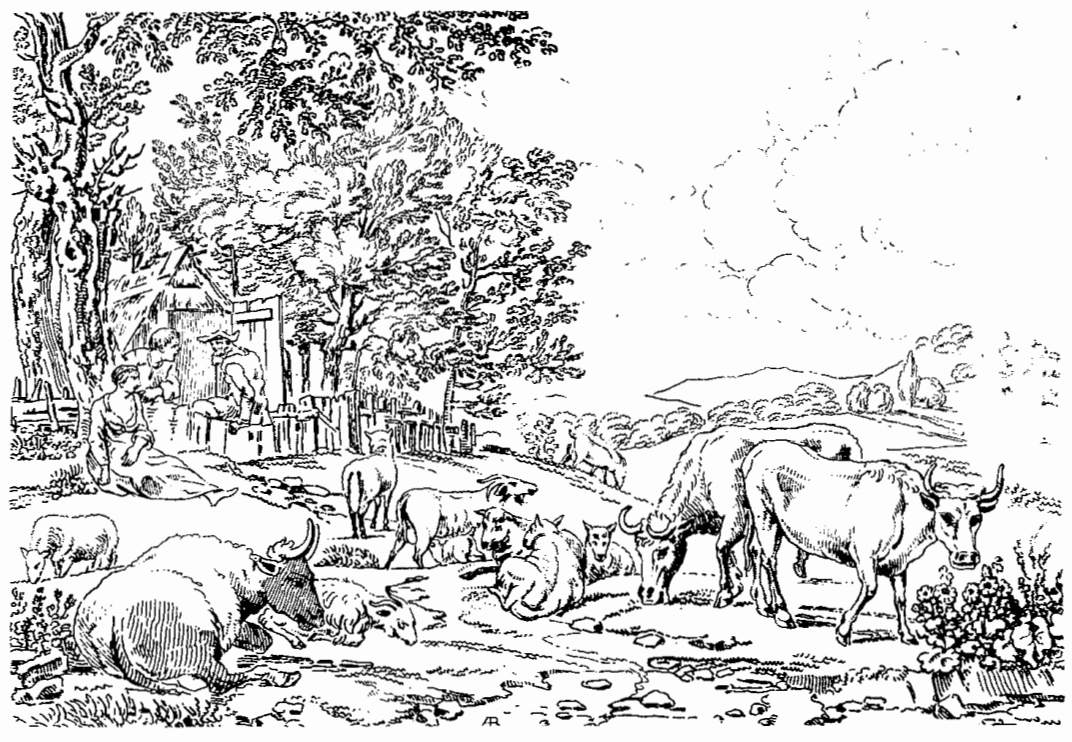

Este nuevo papel del municipio, puede ser teóricamente cumplido gracias a que, como producto de la reforma municipal, cuenta con mayores recursos financieros; se ha dado una reforma en la distribución de los recursos entre los tres niveles de gobierno y se prevé que así el municipio contará con recursos propios para promover el desarrollo sin depender totalmente de las instancias superiores de gobierno.

El nuevo municipio de Nayarit, cuyo presupuesto fue proyectado teniendo en cuenta los mismos conceptos y tarifas que contempla la Ley de Ingresos del municipio de Compostela (al que pertenecían las localidades que hoy conforman el nuevo municipio, mismo que junto con el de Tepic y Santiago concentraron, a lo largo del periodo 1975-1982 los mayores ingresos brutos municipales, aproximadamente $50 \%$ del total de ingresos brutos municipales) parece iniciar su gestión con una capacidad financiera medianamente aceptable y con alentadoras expectativas en la recaudación de impuestos por la prestación de servicios básicamente.

\section{DESCENTRALIZACIÓN ADMINISTRATIVA}

Hablar de descentralización remite a pensar en la posibilidad de una redistribución del poder entre los diferentes niveles de gobierno, en donde el 
municipio deberá jugar un papel más activo en el acercamiento con la sociedad civil. En 1982, ante la profunda crisis económica, los municipios comenzaron a ser objeto de atención en la tarea de promover el desarrollo.

Para ello se requería dotar de poder a la institución municipal e iniciar un proceso de distribución y descentralización de funciones y recursos; éste fue precisamente el argumento utilizado por el gobierno estatal para impulsar la creación del nuevo municipio.

Se promovieron entonces, a nivel nacional, las reformas al artículo 115 constitucional que se aprobaron en febrero de 1983, mismas que ampliaron el poder y las funciones del gobierno municipal, propiciando la participación de la comunidad en las decisiones y las tareas de su desarrollo.

De manera general se puede destacar el contenido del artículo 115 en lo que se refiere al municipio y a su papel en el desarrollo económico:

La fracción tercera menciona que el municipio tendrá a su cargo la prestación de los principales servicios públicos, como agua potable y alcantarillado, limpia, mercados, rastros, seguridad pública y tránsito, etcétera.

La fracción cuarta establece la libre administración de su hacienda y le permite obtener ingresos a partir de. la prestación de servicios y de la captación de recursos fiscales. Los presupuestos de egresos serán aprobados por los ayuntamientos con base en sus ingresos disponibles. Por su parte, la fracción quinta faculta a los municipios para formular, aprobar y administrar la zonificación y planes de desarro- llo urbano municipal, controlar y vigilar la utilización del suelo en sus jurisdicciones territoriales, intervenir en la regularización de la tenencia de la tierra urbana, etcétera.

Como resultado de estas reformas, el poder del municipio tiene cuatro vertientes fundamentales: ${ }^{7}$

1) El poder de la comunidad para organizarse de manera libre y autónoma. Poder para organizarse en lo político y en lo administrativo.

2) Poder de la comunidad municipal sobre su territorio para planear y decidir su uso.

3) Poder para generar el bienestar de la comunidad urbana y rural a través de más y mejores servicios públicos.

4) Poder para establecer relaciones con entidades públicas, sociales y privadas, a fin de coordinarse y aprovechar mejor los recursos que le aporten esas entidades y la propia comunidad para cumplir sus nuevas funciones asistenciales, así como asumir progresivamente el proceso de descentralización de la administración pública federal y estatal y el proceso global de descentralización de la vida nacional.

La segunda vertiente es sin duda la que reviste mayor importancia para la administración municipal que apenas nace; ésta parece ser la que lo justifica. La anterior cabecera municipal estaba muy alejada geográficamente de las localidades donde el territorio y sus usos están sufriendo continuas modificaciones, que necesitan la aprobación legal del municipio, por lo que es necesario acercarla. Además la prestación

\footnotetext{
7 Véase Los municipios, 1988.
} 
de los servicios básicos en la región de Bahía de Banderas había estado a cargo del fideicomiso Bahía de Banderas, al que ahora se descargará de la misma con el fin de que mejore su funcionamiento en otras áreas.

La cuestión de las finanzas para su sostenimiento no parece ser un problema grave dentro de la situación de crisis que se vive, ya que gracias a las reformas, ahora el municipio puede asociarse con diferentes entidades para obtener ingresos o a través de la vía fiscal.

Este proceso de descentralización tiene como condición y efecto, la modernización del poder municipal, la cual implica un conjunto de modificaciones que van desde nuevas técnicas administrativas, acordes con ese proceso, hasta las de carácter ideológico, político, cultural y territorial.

Descentralización y modernización son dos procesos que abarcan distintos aspectos que deben ser considerados de manera integral; modernizar no consiste solamente en

introducir métodos, técnicas y procesos nuevos en la organización administrativa y en el funcionamiento de los gobiernos locales, sino en cuestionar sistemáticamente la posición y el papel que les están asignados en el sistema gubernamental del país $[\ldots] \mathrm{im}$ plica además cuestionar el proceso de toma de decisiones, de manera de involucrar a la participación ciudadana en el establecimiento de prioridades y en ta distribución de los beneficios sociales de la acción gubernamental. ${ }^{8}$ p. 185 .

${ }^{8}$ Lordello de Mello, "Modernización", 1983.

BAHÍA DE BANDERAS: NUEVO MUNICIPIO, VIEJA DEMOCRACIA 
Su planteamiento era que no se necesitaba crear un nuevo municipio porque en el existente estaban repre. sentados los intereses de todos los po. bladores, además se rompe la estructura administrativa que históricamente se había conformado -era pues, según su opinión, un movimiento separatista que respondía a los intereses de un reducido grupo de personas.

En ocasiones se menciona que, detrás del grupo de Medina Lomelí, se encuentran los intereses de Emilio M. González Parra, ex gobernador del estado, quien nunca dio paso a la propuesta, respetando de esa manera los espacios de poder de los líderes tradicionales.

Pero la decisión del gobierno del es- tado con Celso Humberto Delgado se mantuvo firme, su justificación fue la de llevar a cabo la descentralización administrativa, que después se convirtió en la de los nuevos grupos políticos que estaban luchando por tener un espacio formal de poder.

Por otra parte, la discusión acerca del nuevo municipio representa la lucha entre dos estructuras económicas diferentes por tener dentro de su radio de acción a la nueva cabecera municipal: una es la que se encuentra en Valle de Banderas y que está basada en una agricultura comercial, tecnificada y con infraestructura de riego. La otra es la conformada por las localidades costeras donde se asientan fuertes intereses ligados a la actividad turística.

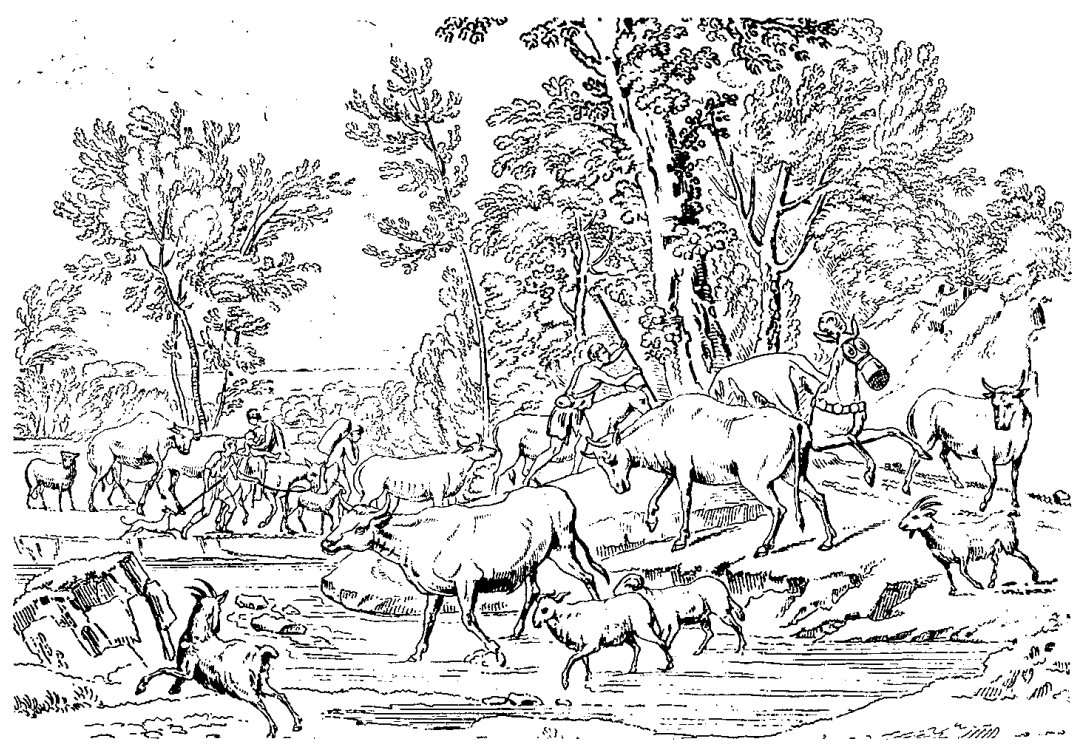




\section{CONCLUSIONES}

La creación del nuevo municipio ha llevado a que se presente una tendencia a la profundización de la desigualdad municipal pues se está propiciando el surgimiento de un municipio con una base económica medianamente sólida $\multimap$ muy sólida si se considera a municipios tales como los de la región serrana de la entidad-gracias a los ingresos por concepto de prestación de servicios turísticos.

Actualmente uno de los graves problemas que enfrentan varias de las localidades de la región es el de los asentamientos irregulares. Esto dado que las obras realizadas por el fideicomiso Bahía de Banderas en la década de los setenta por un lado, sólo respondie. ron a las necesidades del momento sin tomar en cuenta el crecimiento de la población, misma que, por otro lado, ha aumentado considerablemente por las expectativas de crecimiento que ha propiciado la llegada a dichas localida. des de personas tanto del propio estado de Nayarit como de otros, con la idea de encontrar un empleo en la prestación de servicios.

En términos de población, también se debe señalar que debido a las edades predominantes dentro de la misma-población joven-el municipio enfrenta una fuerte demanda de servicios, tales como los relacionados con educación y salud, a los que en el corto y mediano plazo se sumarán los de vivienda y empleo.

En otro aspecto, en las localidades que son atravesadas por la carretera federal núm. 200, sólo la margen derecha de éstas fue urbanizada, ya que es el asentamiento original de dichas poblaciones; pero se han dado ya asentamientos irregulares en la margen izquierda que carecen totalmente de infraestructura y existen pocas esperanzas de que se introduzca en el corto plazo, dado los elevados costos resultantes de las propias características de los terrenos.

Lo anterior es muy notorio para el caso de Bucerías y la Peñita de Jaltemba, donde estos asentamientos irregulares se han dado en terrenos expropiados por el fideicomiso y en los que no se ha realizado ninguna obra. Estos asentamientos -invasiones urbanas-alentados por partidos políti$\cos$, entre los que sobresalen el PRI, el PPS y el PRD, han dado lugar a fuertes conflictos entre los habitantes que los han llevado a cabo y los ejidatarios expropiados que nunca recibicron indemnización. Por ello, a través de la Unión de Ejidos, estaban planteando volver a ocupar sus terrenos.

El surgimiento de un gran número de vendedores ambulantes y, en general, de todos aquellos que realizan actividades de lo que se conoce como economía informal, ha dado lugar a una tendencia a la apropiación de espacios que les son necesarios para realizar sus operaciones, lo que los pone en conficto con las fuerzas o sectores sociales de la región.

Lo anterior se da debido a las expectativas de empleo en la prestación de servicios en las localidades costeras del municipio, que llevan -como se mencionó antes-a la migración de trabajadores, que puede ser temporal pero que generalmente termina por ser permanente. 
En términos de beneficios a la población, como resultado de la creación del nuevo municipio, éstos han sido realmente pocos o nulos, pues habitantes de diferentes localidades manifiestan no haber percibido ningún cambio desde que sus localidades ya no pertenecen a Compostela. El acercamiento de la gestión municipal a la población, con el objeto de propiciar una solución más rápida a los problemas que los aquejan, se ha quedado una vez más en un planteamiento retórico por parte del gobierno.

Pero sí ha respondido a las necesidades del nuevo modelo de acumulación, de ahí que las autoridades estén más ocupadas en su relación con el fideicomiso Bahía de Banderas y en la supervisión de las ventas de terrenos, así como en la llegada de nuevas inversiones extranjeras en el ramo del turismo. La idea de crear un sistema administrativo completamente computarizado-que ni siquiera en la capital del estado se tiene-, responde en términos teóricos a una modernización de la gestión municipal que no incluye la modernización de las prácticas del ejercicio del poder ni la de las relaciones entre la sociedad civil y el gobierno.

La percepción de los cambios en virtud de la existencia de un nuevo municipio, no es la misma para la elite política que para la económica locales.
En principio la creación del nuevo municipio abrió la lucha por el control de un nuevo espacio formal para el ejercicio del poder. Ello propició con. flictos dentro del Partido Revolucionario Institucional y, en especial, entre los dos grupos políticos más importantes de la entidad: el lidereado por el actual gobernador, Celso Humberto Delgado, quien impulsó y llevó a cabo la aprobación legal de dicha creación, y el comandado por el actual presidente de la gran comisión del Senado de la República y ex gobernador de Nayarit, Emilio M. González Parra, cuyos seguidores tienen fuertes intereses económicos y políticos en las localidades que fueron segregadas $y$ que se opusieron tajantemente a esta creación, dado que con ella su espacio de acción real se reduce.

\section{BibLIOGRAFÍA}

-Lordello de Mello, Diego, "Modernización de los gobiernos locales en América Latina", Resista Interamericana de Planificación, vol. XVII, núm. 66, junio de 1983.

-Los municipios de Nayaril, Secretaría de Gobernación-Gobierno del Estado de Nayarit, 1988.

-Secretaría de Programación y Presupuesto, Estudio socioeconómico, municipio de Babia de Banderas, Tepic, septiem. bre de 1990.

-XXII Legislatura, Nuestros municipios, Congreso del Estado de Nayarit, Tepic, 1989. 